\title{
DESIGN OF NEW GRINDING DEVICE FOR HOMOGENIZATION OF MECHANICAL GRINDING METALLURGY PROCESS
}

\author{
Aleš SLÍVA, Robert BRÁZDA \\ VSB - Technical University of Ostrava, Ostrava, Czech Republic, EU, ales.sliva@vsb.cz
}

https://doi.org/10.37904/metal.2020.3615

\begin{abstract}
The paper deals with an experience with innovation process of a technical solution of grinding device for homogenization of mechanical grinding metallurgy process. Milling equipment-ball mills and planetary ball mills are used for conventional mechanical material milling. Their principle is based on very fine milling of the material. As with other milling equipment, there is a milling effect by combining three factors: pressure, impact, and smearing. A major disadvantage of the previously used milling equipment is the fact that during the milling process, due to the pressure and impact of the grinding bodies, agglomerates and aggregates have been formed to a chamber wall and thus significantly reduce the efficiency of the milling process. The formation of aggregates and agglomerates is an adverse effect in the processing of fine particulate materials, respectively nanopowders.

The main advantage of the invented design can be seen in the simplicity of the device, which results in the homogenization of the processed material and also in the multifunctionality of the device, whereby the device does not restrict the conditions under which the mechanical process has been used so far, i.e. it allows grinding to be done with or without adding a liquid inert phase.
\end{abstract}

Keywords: Metallurgy, innovation process, homogenization, grinding device

\section{INTRODUCTION}

Milling equipment-ball mills and planetary ball mills are used for conventional mechanical material milling $[2,4,8,10]$. Their principle is based on very fine milling of the material. As with other milling equipment, there is a milling effect by combining three factors: pressure, impact, and smearing. A major disadvantage of the previously used milling equipment is the fact that during the milling process, due to the pressure and impact of the grinding bodies, agglomerates and aggregates have been formed to a chamber wall and thus significantly reduce the efficiency of the milling process. The formation of aggregates and agglomerates [22] is an adverse effect in the processing of fine particulate materials, respectively nanopowders [1,6,7,13,27-29]. As with other grinding equipment mentioned by authors $[9,11,16,21,26,31,32]$, there is a grinding effect taking place by combining factors: pressure, impact, attrition, size distribution, electrical discharge, fluidization etc. also described by authors $[3,17,18-20,23,24]$ or factors dependence on material fine powder and nanocomposite processing referred by authors $[5,6,7]$.Special chapter in the process of material processing is innovation processes and technical solutions of apparatus for processing metals of loose nature tending to air oxidation, especially alkaline earth metals $[30,33,34]$. The aim of this technical solution is to design a device facilitating the process of treating rare earth metals in a way that would prevent their air oxidation and thus facilitate their handling in the next technological process $[14,15,25]$.

In principle, materials with a plurality of grinding bodies are inserted into the milling chamber of the ball mill. During milling, the milling chamber is rotated, whereby the grinding bodies in the chamber rotate and rotate, thereby milling or pulverizing the material. In addition, in the case of planetary ball mills, an extremely large 
centrifugal force is created which contributes to the different movement of the milling bodies against the milling chamber, which significantly reduces the milling time.

A major disadvantage of the previously used milling equipment is the fact that aggregates and agglomerates or sticky layers are formed during the milling process due to the pressure and impact of the milling bodies on the wall of the milling chamber, which significantly reduces the efficiency of the milling process. The formation of aggregates and agglomerates has an adverse influence on the processing of fine particulate materials or nanopowders. These sticky layers cannot be removed during the process, except by completely stopping the milling process, disassembling the milling device and mechanically wiping away the sticky layer. The result is an inhomogeneously ground or comminuted material with a varied particle size distribution of the material being processed.

This markedly reduces the efficiency of the grinding process. To remove the layers that became stuck the process has to be completely interrupted, the grinding device dismantled, and the layers stuck to the wall mechanically scraped off. The result is an inhomogeneously ground/pulverized material with varying distribution of different particle sizes of the processed material as shown in the work [29].

In order to avoid the above-mentioned problems, the construction of the ball mill was supplemented with a mixing device or cleaning/scraping blade with special metal testing material $[5,12]$, which is fixed in the central part of the mill and thus helps to remove sticky layers from the walls of the milling vessel. These directions are represented in, for example, the following documents: US4673134 (A) - 1987-06-16, EP0627262 (A1) - 199412-07 or US3027105 (A) - 1962-03-27, which focus on the classical treatment of material by mixing the material in a closed space by means of a set of rotary shafts with carriers or by mixing the material in space with a shaft provided with mixing carriers. However, this mixer / scraper does not allow for variable adjustment of its arms and also does not solve the problem of material sticking on the mixer / scraper itself.

Further modifications to the milling device presented in WO2008088100 (A1) - 2008-07-24 and US4645133 (A) - 1987-02-24 were directed towards modification of the surface of internal milling drum and thus the material impact efficiency of the milling process. Also, the documents US1726917 (A) - 1929-09-03, US2761628 (A) 1956-09-04 focus on an area of targeted development of a comb-like or other drum profile, including the rotation mechanism itself.

\section{ESSENCE OF THE INVENTION}

The above disadvantages are largely eliminated by the variable fluidizing blade of the ball mill. The invention addresses the process of treating the material directly in the milling apparatus of the ball mill and effectively adjusts the material milling process itself by means of adjustable blades located on the inner circumference of the ball mill drum.

\subsection{Technical solution}

The basic innovative element of the device is the blade of the outer drum of the ball mill, which forms a variable angle with the drum wall by means of a pin. By varying the angle of rotation of the blade, the angle of inflow of material into the inner space of the drum is directly controlled when it is rotated, thereby directly controlling a more efficient way of material falling into the drum space. The angle of landing can be directly controlled by knowing the mechanical-physical and geometric properties of the milling material. The advantage of this solution is the direct adjustment of the impact energy of the material and thus the reduction of the economic demands of the material milling process.

The abovementioned adjustable ball mill blade is provided with internal channels allowing input of a fluidizing medium, which may be air, liquid or a combination thereof (vapor), resulting in another possibility of process treatment of the material during crushing, by, for example, fluidization of the material, inflow of fluid (or potentially gas into the ducts) into the blade ducts. 
Another important effect of fluidization is also to minimize the sticking of very fine material on the vessel walls or on the blades themselves.

\section{CLARIFICATION OF DRAWINGS}

\subsection{A ball mill (horizontal design) and an arrangement of the exterior of the device}

Figure 1 illustrates a ball mill (horizontal design) and an arrangement of the exterior of the device. Figure 2 shows a section of the interior of the device.

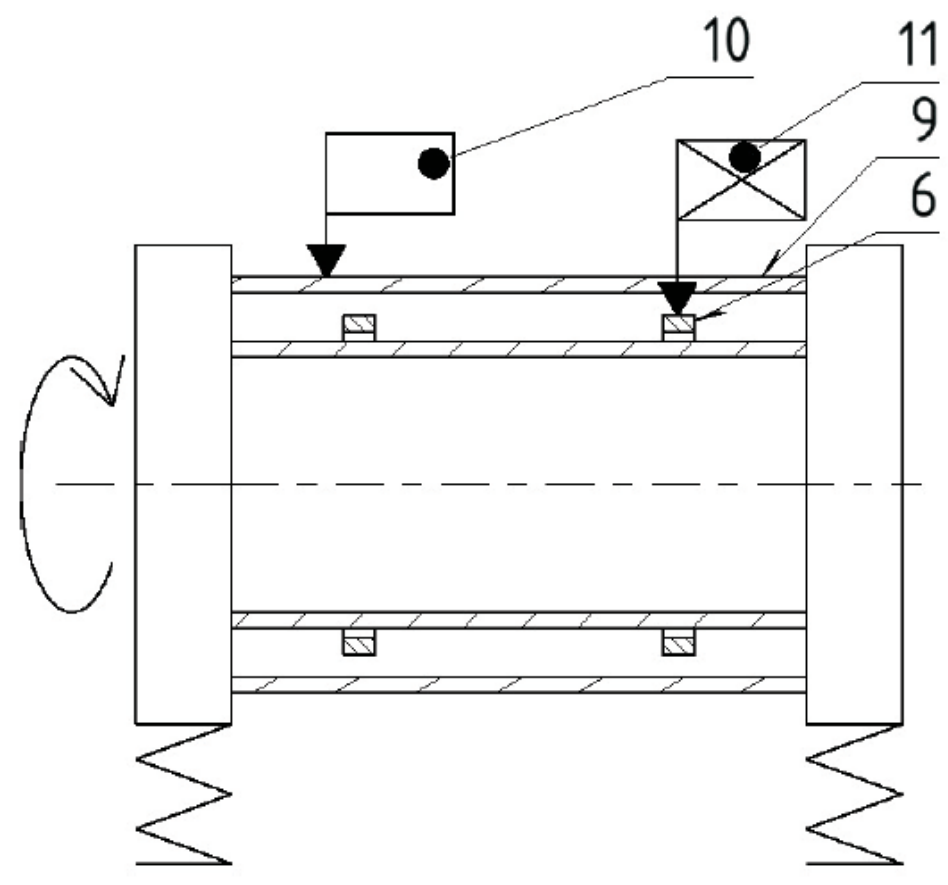

Figure $1 \mathrm{~A}$ ball mill (horizontal design) and an arrangement of the exterior of the device

\subsection{A section of the interior of the device}

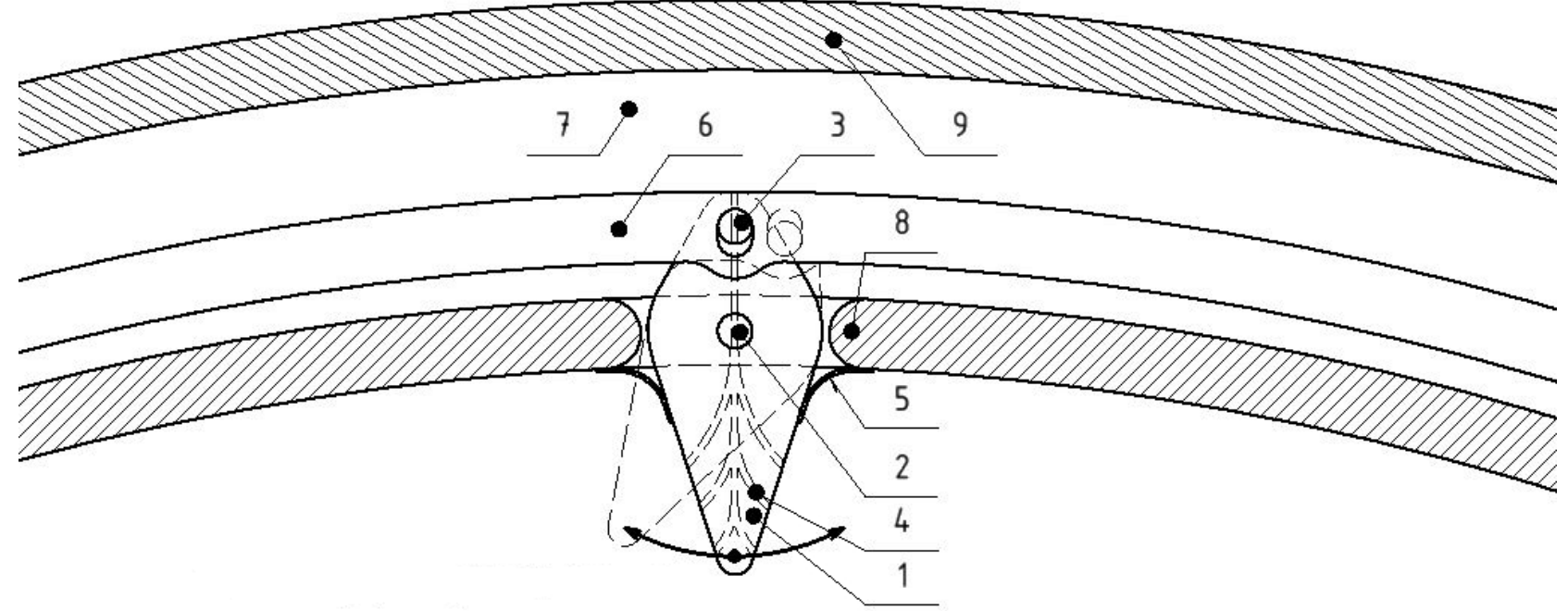

Figure 2 A section of the interior of the device 


\section{EXECUTION EXAMPLE}

Between the shell of the ball mill and the drum 8 there is a fluidizing space 7 which is connected by an inlet with a compressor 10 for supplying fluidizing medium. A movable ring 6 for adjusting the blade angle 1 abuts the fluidizing space 7 . The blade 1 is fixed to the ring 6 by means of a tilt adjustment pin 3 and then passes through the drum 8 and subsequently, through the sealing sleeve 5 , into the ball mill. From the fluidizing space 7 , the fluidizing channels 4 lead through the blade 1 into the space of the drum 8 . The vane 1 is fixed in the drum 8 by a securing pin 2 . The servomotor 11 located on the surface of the mill shell 9 is connected to the ring 6 controlling the movement of the blade 1 .

The blade 1 can be rotated and extended / retracted by the movement of the ring 6 . In any rotation, the angle of impact of the material changes and thus even the material crushing mechanism.

\subsection{Patent Claims}

- $\quad$ A ball mill with a fluidizing device located in the wall of the mill drum (8), characterized in that a fluidizing medium supply compressor (10) and a servo motor (11) for controlling the movable ring (6) are provided on the ball mill housing (9) to provide variable movement of at least one blade (1) with fluidizing channels

(4) extending through the drum wall (8).

- A ball mill with a fluidizing apparatus placed in the wall of the mill drum (8) according to claim 1 , characterized by the fact that a fluidizing space (7) is located beneath the shell (9), a movable ring (6) for variable movement of the blade (1) which is adjacent to drum (8).

- $\quad$ A ball mill with a variable fluidization apparatus located in the wall of the mill drum (8) according to claims 1 and 2, characterized by the fact that the blade (1) passes through a sealing sleeve (5) and further through the drum wall (8) in which it is fastened by a locking pin (2) and is partially embedded in the ring (6) where it is fixed by a pin (3) to adjust its angle of inclination.

- $\quad$ A ball mill with a variable fluidization apparatus located in the wall of the mill drum (8) according to claims 1 and 2, is characterized by the fact that fluidizing passages (4) pass through the blade (1) and pass through the skirt (6) and into the fluidizing space (7), which is connected to a compressor (10) for injection of the fluidizing medium.

\section{CONCLUSION}

In this paper, the methodology of innovation of a ball mill design with a fluidization device equipment for of patent in cooperation with the commercial sector under the auspices of the university. The main objective was the equipment innovation from the draft idea through the cooperation with the patent representative and the university as far as to finding of a commercial partner for the registered patent.

The device can be used in the treatment of particulate materials - crushing of individual particles (grinding e.g. mineral) and at the same time can be used for example in the food industry or pharmaceutical industry for mixing various materials and forming dry mixtures. The device can be used in horizontal and vertical mills. Optionally for aeration of materials such as sludge.

(Source:https://worldwide.espacenet.com/publicationDetails/biblio?DB=EPODOC\&Il=0\&ND=3\&adjacent=tru e\&locale $=$ en $E P \& F T=D \& d a t e=20180808 \& C C=C Z \& N R=2017506 A 3 \& K C=A 3$ )

\section{ACKNOWLEDGEMENTS}

The article was created with the support of Student Grant Competition SP2020 / 90 - Research in the Field of Transport and Process Systems and Technologies. 


\section{REFERENCES}

[1] BROZOVA, S., DRAPALA, J., KURSA, M., PUSTEJOVSKA, P., JURSOVA, S. Leaching refuse after sphalerite mineral for extraction zinc and cobalt. Metalurgija. 2016, vol. 55, iss. 3, pp. 497-499. ISSN 0543-5846.

[2] BURMEISTER, C., TITSCHER, L., BREITUNG-FAES, S., KWADE, A. Dry grinding in planetary ball mills: Evaluation of a stressing model. Advanced Powder Technology. 2018, vol. 29, no. 1, pp. 191-201. DOI: 10.1016/j.apt.2017.11.001.

[3] CAI, L., LI, X., G., LIU, W., L., MA, B., G., LV, Y.The slurry and physical-mechanical performance of autoclaved aerated concrete with high content solid wastes: Effect of grinding process. Construction and Building Materials. 2019, vol. 218, pp. 28-39.DOI: 10.1016/j.conbuildmat.2019.05.107.

[4] CALKA, A. WEXLER, D. (2002). Mechanical milling assisted by electrical discharge. Nature. 2002, vol. 419, no. 6903, pp. 147-151.DOI: 10.4028/www.scientific.net/JMNM.20-21.111.

[5] CEP, R., JANASEK, A., SLIVA, A., NESLUSAN, M., BINDER, M.Experimental tool life tests of indexable inserts for stainless steel machining. Tehnickivjesnik-technical gazette. 2013, vol. 20, no. 6, pp. 933-940.

[6] DVORSKY, R., LUNACEK, J., SLIVA, A., SANCER, J. Preparation of silicon nanoparticular nanocomposite with thin interparticular tin matrix. Journal of nanoscience and nanotechnology. 2011, vol. 11, no. 10, pp. 9065-9071. DOI: 10.1166/jnn.2011.3510.

[7] DVORSKY, R., SLIVA, A., LUNACEK, J., PIKSOVA, K.Preparation of silicon nanoparticles by means of disintegration in a cavitation water jet, 2nd NANOCON International Conference. Olomouc, Czech Republic,TANGER Ltd, OCT 12-14, 2010, pp. 144-150.

[8] FADDA, S., CINCOTTI, A., CONCAS, A., PISU, M. AND CAO, G. Modelling breakage and reagglomeration during fine dry grinding in ball milling devices. Powder Technology. 2009, vol. 194, no. 3, pp. 207216.DOI: 10.1016/j.powtec.2009.04.009.

[9] GUO, B., ZHAO, Q.. Mechanical truing of V-shape diamond wheels for micro-structured surface grinding. International Journal of Advanced Manufacturing Technology. 2015, vol. 78, no. 5, pp. 10671073.DOI: $10.1007 /$ s00170-014-6721-7

[10] JI, R., LIU, Y., ZHANG, Y., WANG, F., CAI, B., DONG, X.Machining Performance Optimization in End ED Milling and Mechanical Grinding Compound Process. Materials and Manufacturing Processes. 2012, vol. 27, no. 2, pp. 221-228.DOI: 10.1080/10426914.2011.568569.

[11] JIANG, J., GE, P., SUN, S., WANG, D., X., WANG, Y., L., YANG, Y.From the microscopic interaction mechanism to the grinding temperature field: An integrated modelling on the grinding process. International Journal of Machine Tools \& Manufacture. 2006, vol. 110, pp. 27-42.DOI: 10.1016/j.ijmachtools.2016.08.004.

[12] JONSTA, P., VANOVA, P., BROZOVA, S., PUSTEJOVSKA, P.,SOJKA, J., JONSTA, Z., INGALDI, M. Hydrogen embrittlement of welded joint made of supermartensitic stainless steel in environment containing sulfane. Archives of Metallurgy and Materials. 2016, vol. 61, no. 2, pp. 709-711. DOI: 10.1515/amm-2016-0121.

[13] JOSSET, S., ORSOLINI, P., SIQUEIRA, G., TEJADO, A., TINGAUT, P., ZIMMERMANN, T. Energy consumption of the nanofibrillation of bleached pulp, wheat straw and recycled newspaper through a grinding process. Nordic Pulp \& Paper Research Journal. 2014, vol. 29, no. 1, pp. 167-175.DOI: 10.3183/npprj2014-29-01-p167-175.

[14] JURSOVA, S., PUSTEJOVSKA, P., BROZOVA, S. Study on reducibility and porosity of metallurgical sinter. Alexandria Engineering Journal. 2018, vol. 57, no. 3, pp. 1657-1664.DOI: 10.1016/j.aej.2017.03.007.

[15] KARDAS, E., BROZOVA, S., PUSTEJOVSKA, P., JURSOVA, S. The evaluation of efficiency of the use of machine working time in the industrial company - case study. Management systems in production engineering. 2017, vol. 25, no. 4, pp. 241-245.DOI: 10.1515/mspe-2017-0034.

[16] KULIK, O., G., DEMENKOV, V. A. Kinematics and Dynamics of Chip Formation during Grinding. In International Conference on Industrial Engineering (ICIE 2017). Saint Petersburg, RUSSIA: Procedia Engineering, 2017, pp. 210-215.DOI: 10.1016/j.proeng.2017.10.462.

[17] LU, X., HOLLAND, D. J. Investigation of drag models for the two fluid simulation of Geldart group A powders. Advanced Powder Technology. 2016. vol. 304, pp. 41-54. DOI: 10.1016/J.POWTEC.2016.07.063.

[18] MA, H., XU, L., ZHAO, Y. CFD-DEM simulation of fluidization of rod-like particles in a fluidized bed. Advanced Powder Technology. 2017. vol. 314, pp. 355-366. DOI: 10.1016/J.POWTEC.2016.12.008. ISSN: 0032-5910. 
[19] MAKKAWI, Y., T., WRIGHT, P., C. The voidage function and effective drag force for fluidized beds. Chemical Engineering Science. 2003, 58, iss. 10, pp. 2035-2051. DOI: 10.1016/S0009-2509(03)00054-X. ISSN: 0009-2509.

[20] MALONE, K. F., XU, B. H. Particle-scale simulation of heat transfer in liquid-fluidised beds. Advanced Powder Technology. 2008. vol. 184, iss. 2, pp. 189-204. DOI: 10.1016/J.POWTEC.2007.11.043. ISSN: 0032-5910.

[21] MUCSI, G. Fast test method for the determination of the grindability of fine materials. Chemical Engineering Research \& Design. 2008, vol. 86, no. 4A, pp. 395-400.DOI: 10.1016/j.cherd.2007.10.015.

[22] MUELLER, G. E. Numerically packing spheres in cylinders. Advanced Powder Technology. 2005. vol. 159, iss. 2, pp. 105-110. DOI: 10.1016/J.POWTEC.2005.06.002.

[23] PANNEERSELVAM, R., SAVITHRI, S., SURENDER, G., D. CFD based investigations on hydrodynamics and energy dissipation due to solid motion in liquid fluidised bed. Chemical Engineering Science. 2007. Vol. 132, iss.1-3, pp. 159-171. DOI: 10.1016/j.cej.2007.01.042.

[24] PUGSLEY, T., S., MILNE, B., J., BERRUTI, F. An innovative non-mechanical solids feeder for high solids mass fluxes in circulating fluidized bedrisers. Advanced Powder Technology. 1996. vol. 88, pp. 123-131.

[25] SEVOSTYANOV, V. S., URALSKIJ, V. I., URALSKIJ, A. V., SINITSA, E. V. Multifunctional centrifugal grinding unit. In $11^{\text {th }}$ International Conference on Mechanical Engineering, Automation and Control System, Tomsk, Russia: Proceedings Paper, 2017, pp. 327.DOI: 10.1088/1757-899X/327/4/042112.

[26] RUDOLF, L., FRIES, J. Design issues of grinding machine spindle used for the interior diameters of long pipes. In 16th International Multidisciplinary Scientific Geoconference (SGEM 2016), Albena, BULGARIA:Proceedings Paper, 2016, pp. 255-262.

[27] SLIVA, A., BRAZDA, R., PROCHAZKA, A., MARTYNKOVA, G., S., BARABASZOVA, K., C. Study of the optimum arrangement of spherical particles in containers having different cross section shapes. Journal of Nanoscience and Nanotechnology, 2019, vol. 19, no. 5, pp. 2717-2722. DOI: 10.1166/jnn.2019.15873.

[28] SLIVA, A., BRAZDA, R., PROCHAZKA, A., MARTYNKOVA, G., S., BARABASZOVA, K., C. Investigation of geometric properties of modified titanium white by fluidisation for use in the process of transport, handling, processing and storage. Journal of Nanoscience and Nanotechnology. 2019, vol. 19, no. 5, pp. 29973001.DOI: 10.1166/jnn.2019.15872.

[29] SLIVA, A., SAMOLEJOVA, A., BRAZDA, R., ZEGZULKA, J., POLAK, J. Optical parameter adjustment for silica nano and micro-particle size distribution measurement using mastersizer 2000. Microwave and Optical Technology. 2003, vol. 5445, pp. 160-163. DOI: 10.1117/12.558761.

[30] THIEBAUD, E., HILTY, L., M., SCHLUEP, M., BONI, H., W., FAULSTICH, M. Where do our resources go? Indium, neodymium, and gold flows connected to the use of electronic equipment in Switzerland. Sustainability. 2018. vol. 10, iss. 8.Article Number: 2658. ISSN: 2071-1050. DOI: 10.3390/su10082658.

[31] WANG, C., FANG, Q., CHEN, J., LIU, Y., JIN, T. Subsurface damage in high-speed grinding of brittle materials considering kinematic characteristics of the grinding process. International Journal of Advanced Manufacturing Technology. 2016, vol. 83, no. 5-8, pp. 937-948.DOI: 10.1007/s00170-015-7627-8.

[32] WANG, Y., ZHANG, W., LIU, Y.Analysis model for surface residual stress distribution of spiral bevel gear by generating grinding. Mechanism and Machine Theory. 2018, vol. 130, pp. 477490.DOI: 10.1016/j.mechmachtheory.2018.08.027.

[33] WUEBBEKE, J.Rare earth elements in China: Policies and narratives of reinventing an industry. Resources Policy. 2013. vol. 38, iss. 3, pp. 384-394. DOI: 10.1016/j.resourpol.2013.05.005. ISSN: 03014207. DOI: 10.1016/j.resourpol.2013.05.005.

[34] YAM, Y., X., AHMAD T., ZHANG, X., L. T., REHMAN, S., MANZOOR, M. U., LIU, W., BASIT, M., A. Microstructure, hardness and corrosion behavior of $\mathrm{Ni}$-Ti alloy with the addition of rare earth metal oxide $\left(\mathrm{Gd}_{2} \mathrm{O}_{3}\right)$. Materials Research Express. 2019. vol. 6, iss. 7, pp. Article Number: 076513.DOI: 10.1088/20531591/ab1159.DOI: 10.1088/2053-1591/ab1159. 